\title{
Asset-Based Strategies for Capturing Value in the Service Economy
}

\author{
Jochen Wirtz and Michael Ehret ${ }^{1}$
}

\section{Forthcoming in:}

Jochen Wirtz and Michael Ehret (2018), “Asset-Based Strategies for Capturing Value in the Service Economy”, in Maglio, P. P., Kieliszewski, C. A., Spohrer, J. C., Lyons, K., Patricio, L. \& Sawatani, Y. (Eds.). (in press). Handbook of Service Science, Volume II. New York: Springer. ISBN 978-3-319-98511-4 (hardcover)

July 6, 2018

\footnotetext{
${ }^{1}$ Jochen Wirtz is Vice-Dean Graduate Studies and Professor of Marketing at the National University of Singapore; email: jochen@nus.edu.sg. Michael Ehret is Reader in Technology Management at Nottingham Business School, Nottingham Trent University, United Kingdom; email michael.ehret@ntu.ac.uk.
} 


\title{
Asset-Based Strategies for Capturing Value in the Service Economy
}

\begin{abstract}
In advanced service economies, almost any activity, skill, and asset can be bought on competitive markets, making it increasingly difficult to build competitive advantage on any of those inputs. Therefore, firms have to carefully decide what to own in order to capture value. That is, firms have to explore what types of assets can add value to their customers and at the same time are difficult or illegal to copy by competition. We examined this question and identified asset categories that potentially allow a firm to appropriate value. They are (1) resource-based assets (e.g., proprietary equipment and systems, manufacturing-related intellectual property (IP), and social capital with employees); (2) platform-based assets (e.g., physical and intellectual platform assets, and critical mass and volume-based advantages,); and (3) market-based assets (e.g., brands and related brand equity, physical and virtual points-of-sale, access to physical and virtual distribution networks, and customer information and loyalty programs). Furthermore, we propose that each of these three asset categories can take the form of three types of capital. They are (1) tangible capital (i.e., it has a physical manifestation such as equipment and physical points-of-sale); (2) intangible capital (i.e., it can be codified and legally protected such as patents and brands); and (3) social capital (i.e., it is embedded in people's minds and cannot be legally protected such as trust, goodwill and engagement of employees, partners and customers). The three asset types and their three manifestations are integrated into a framework for an asset typology. For example, market-based assets can come in all three forms, that is in tangible (e.g., point-of-sale networks), intangible (e.g., brands), and social (e.g., customer equity) form. Finally, we identified four important organizational capabilities of asset integration that are independent of asset ownership but effectively link owned and outsources assets, capabilities, and processes to value creation and can also allow a firm to capture value. They are (1) business models for designing the architecture and "Gestalt" of value creation; (2) a customer-centric culture and a climate for service; (3) innovation capabilities, and (4) the effective management of an integrated web of processes and activities. We discuss the why and how of this asset typology and its implications for management, strategy, and research.
\end{abstract}

Keywords: Service economy; competitive advantage; competitive strategy; asset ownership; capturing value; value appropriation.

Note: This article draws on and extends the following publications: Michael Ehret and Jochen Wirtz (2018, in print), "Ownership of Cocreation Assets: Driving B2B Value Propositions in the Service Economy,” Journal of Creating Value; and Jochen Wirtz and Michael Ehret (2017), "Capturing Value in the Service Economy”, Journal of Service Management Research, Vol. 1, No. 1, pp. 22 - 38. 


\section{The Rise of Service Business Models and Reconfiguration of Value Chains}

One of the most striking economic phenomena is that the services sector becomes dominant as an economy develops (Buera and Kaboski 2012). Contrary to common belief, economic statistics show that the share of consumer services does not show significant shifts. In fact, in the US the share of consumer services of GDP has remained largely unchanged over time. Rather, it is business services such as finance, logistics, IT services and consulting, that lead the expansion of the service-sector (Ehret and Wirtz 2010; Ndubisi et. al., 2016; OECD 2007; Triplett and Bosworth 2003) and are the key motor behind the growth of the service sector (OECD 2007; Woelfl, 2005). Debates of the service economy have ignored for too long that innovation and restructuring of business services work as the main driver of economic growth (Ehret and Wirtz 2010; OECD 2007; Wirtz et al. 2015; Woelfl 2005).

In advanced service economies, almost any activity can be hired as a service (see Figure 1). A broad range of business functions once deemed as mandatory for in-house control are increasingly outsourced. For example, a firm's strategy might be developed by independent consulting companies or even venture capital firms, research and development (R\&D) delegated to external firms, and a substantial extent of the competitiveness of current offerings may reside on the performance of externally-provided supply chains, IT-services and customer contact centers. In fact, the firms offering such services are often unbeatable by in-house departments in terms of their performance, quality, cost of operations, and innovation capability (Ehret and Wirtz, 2010; Wirtz et al. 2015).

\section{[Insert Figure 1 about here]}

This almost wholesale shift towards a service economy has dramatic implications for strategic management. If almost any asset, activity and skill can be outsourced to high- 
performing external service providers, what should a company focus on and assume ownership over to build a competitive advantage and to be able to capture value? In this article, we address these questions by presenting business model approaches for re-configuring value chains, discussing the role of specific asset types for value appropriation, and explaining management approaches that might offer potential for developing a competitive edge.

\section{Service Business Models and Asset Ownership}

Industry-driven competitive strategies build on a given structure of established roles like those of upstream suppliers, downstream customers, and distribution channels, as well as competitors and substituting technologies (e.g., Porter 1980). However, service economies are driven by structural shifts and when faced with shifting industry structures, these strategies lose their point of reference. Business model approaches aim to fill this void and offer a dynamic view of hypercompetitive ecosystems that contrast with the industry structure perspective underlying Porter's value chain (Stabell and Fjeldstad 1998; Zott and Amit 2008).

In a service business model, firms deliver benefits without the transfer of ownership (Wirtz and Lovelock 2017, p. 21). Transfer of ownership marks a crucial difference between a goods business, where suppliers transfer ownership of assets like cars or machines to their customers, and service business where providers deliver results to their clients, like transportation to a required location, or uptime and output of a manufacturing line without transferring ownership (Chesbrough 2011; Ehret and Wirtz 2010; Lovelock and Gummesson 2004; Wittkowski et al. 2013).

For providers and their clients, service business models have been opening new pathways for value creation, whereby clients are relieved from the need to own and operate assets. As service clients replace in-house assets and activities with purchasing services, this outsourcing 
offers opportunities for service providers who specialize in managing the resource base (Ehret and Wirtz 2017, 2018).

Service research shows rationale and evidence that service business models deliver benefits from non-ownership for providers, their clients, and the overall economy through productivity gains (Chesbrough 2011; Lovelock and Gummesson 2004; Wittkowski et al. 2013). To date, the focus of service research on non-ownership value has been on the service client's perspective (Lovelock and Gummesson, 2004), understanding intentions to purchase nonownership services (e.g., Wittkowski et al., 2013), and addressing its underlying economic rationale (Ehret and Wirtz 2010, 2017). In that light, it is tempting to view ownership as a burden that bears little value. However, the fast growth of non-ownership services does not mean that ownership disappears. Rather, both managers and researchers have yet to face the supply-side implications of non-ownership in terms of both opportunities and burdens for providers. Thus, strategy research needs to take a deeper look into the conditions that render asset ownership as building block for long-term competitive advantage. In the following section, we take a closer look at the role of assets in value creation and appropriation.

\section{Assets for Value Appropriation}

Service economies put firms under a severe dilemma. As almost any business function, operation or activity becomes available as a service, firms are gaining flexibility and ease of access to resources (Ehret and Wirtz 2010; Quinn 1992). This boon of resources comes with a flip-side that potentially undermines the economic legitimacy of a firm. That is, when assets, resources, and capabilities under control by the firm are easily substituted by competitors, building sustainable competitive advantage becomes even more challenging. Firms need to scrutinize if their assets connect them to opportunities or rather work as baggage for the firm. 
Thus, the challenge for identifying competitive grades of vertical integration shifts from transaction cost efficiency towards opportunities and their implications for asset ownership (Ehret and Wirtz 2010).

In short, to support value appropriation, firms need to own assets that create value for their clients that cannot be copied, take a long time to copy, or are illegal to copy. In this article, we explore how and when key asset types can potentially be the basis for sustainable competitive advantage in advanced service economies.

\section{Asset Types in Value Co-Creation}

While several authors accentuate the supply-driven aspect of the resource-base, its pioneers see resources as crucial links between firms and entrepreneurial opportunities on external markets (Lewin 1999; Penrose 1959). This view finds its echo in the work of researchers who have established the resource-based view as one of the major conceptual foundations of the marketing domain (Morgan and Hunt 1994; Wernerfelt 1984).

Entrepreneurial opportunities are key drivers of resource rents and emerge when customer needs are not addressed or resource potential remains idle (Sharon et al. 2013; Kirzner 1997; Shane and Venkataraman 2000). Under equilibrium, assets can easily be substituted, pushing firms in the position of price takers. Business opportunities are neither objectively nor intrinsically given but emerge through the relation between the needs of customers and the capabilities of the resource-base to serve them. The value of a resource is driven by the relation between its intrinsic capabilities and extrinsic user needs. The key criterion for judging the value of a resource is its potential of being transformed into goods and services that render value-inuse (MacDonald et al. 2016; Vargo and Lusch, 2014).

By considering the potential role of transforming resources into user value, we can 
differentiate between three basic asset categories (see Figure 2). First, market-based assets enable a firm to identify needs, craft product offerings that match identified needs, specify contracts for organizing transactions, and deliver the goods and services. Basic forms of market based-assets include brands and the related brand equity, customer equity, communications channels, and points of sale. Second, resource-based assets relate to capabilities and capacity of production. Basic forms of resource-based assets include equipment, systems, facilities, and manufacturingrelated IP. Third, platform-based assets include physical platforms (e.g., a market place and strategic real estate), virtual platforms (e.g., an electronic market place), which both are frequently protected through network effects and enabled through critical mass or liquidity.

[Insert Figure 2 about here]

For each of these assets, we can identify three basic manifestations or types of capital, namely tangible (or physical), intangible and social capital. First, tangible capital has a physical manifestation and entails assets like equipment, facilities, and points-of-sale (POS) that provide the material basis for differentiating products and their delivery. Such assets play key roles in each stage of the value chain, including setting the scene at the point of customer interaction, in production, and through the physical platforms that connect resources and customers.

Second, intangible capital consists of ideas, knowledge or information that does not have a physical manifestation but is legally protected. At the front end, brands shape the perception and image of products while resource-based IP enhances technological capabilities of production, and platforms entail a growing range of intellectual capital.

Third, social capital, such as trust, goodwill, and engagement of employees, partners, and customers, cannot be legally owned by a firm, which renders it even more precious. Social capital takes the form of human resources and organizational culture and climate in the domain 
of the provider, platform assets mainly in the form of trust, goodwill and engagement of suppliers, partners, and complementors, and not least in customer engagement which constitute market-based social capital.

Because owners are responsible for up- as well as downsides of their asset-base, a selective approach to asset-ownership is critical, and firms need to prioritize on those assets where they can hope to make the highest contribution to their clients. The key to develop, enrich and maintain assets is to energize them by establishing a logic that integrates distinct asset types in a virtuous manner for the benefit of both, providers and their clients. In that regard, we identify four important organizational capabilities of asset integration:

We discuss the why and how of this asset typology and its implications for management, strategy, and research.

Finally, we identified four important organizational capabilities of asset integration that are independent of asset ownership but effectively link owned and outsources assets, capabilities, and processes to value creation and can also allow a firm to capture value. They are (1) business models for designing the architecture and "Gestalt” of value creation; (2) a customer-centric culture and a climate for service; (3) innovation capabilities, and (4) the effective management of an integrated web of processes and activities. We discuss next each of the asset categories.

\section{Resource-Based Assets}

Resource-based assets represent capabilities and capacity of the supply base. One driver of service businesses is the value proposition offered by non-ownership: Clients can get the benefits from resources without the burdens of ownership. The challenge for providers is to bear the ownership of resources as an entry-gate to opportunities. Downsides of ownership do not simply disappear because of a re-allocation of asset ownership from one firm to another. Thus, 
providers need to identify smart ways to bear ownership. Specialization in the management of a particular asset class can offer trajectories for service providers that are out of reach for vertically integrated companies. By specializing on particular types of resources, providers can gain unique positions, differentiate assets, drive cost advantages, and also gain economies of scale and scope, for example, by furnishing general purpose resources across entire industries if not economies.

Resource-Based Tangible Capital: Equipment, Systems, and Facilities. Equipment, systems, and facilities define the capabilities and capacity of a service, providing clout for companies that design, own and operate them. Asset-ownership offers an entrance gate for establishing service and solution businesses for plant, machine, and equipment manufacturers (Ehret and Wirtz 2017). For example, in the domain of industrial production, suppliers have been moving towards owning and operating equipment, machines and even entire plants on behalf of their customers. Examples include chemical company BASF which has been moving to operate its clients' automotive paint shops (Worm et al. 2017), and Rolls Royce commercialized airplane engine services through "power-by-the-hour” contracts. In such performance and solution schemes, providers earn revenue on the output and the benefits generated by industrial assets rather than through selling the assets themselves (Ehret and Wirtz 2017). While relieving their customers from risks associated with industrial assets, these risks remain with the service providers. However, providers who specialize on asset management can build superior experience and resources that empower them to better mitigate and bear uncertainties compared to their clients. They can succeed by building and maintaining an in-depth understanding of the equipment and technology, and a much larger installed base that allows them to invest in smart systems that that enable better quality and more cost-effective operation of equipment and its maintenance and repair (incl. preemptive maintenance and other innovative services based on 
based on AI, big data, and analytics; Ehret and Wirtz 2017). Such integrated solutions, smart systems and taking on risk are much more difficult to copy by competition than individual pieces of equipment and therefore more likely to help develop a competitive edge.

Resource-Based Intangible Capital: Patents and Copyrights. Technology represents human knowledge of resource potential and is driving the performance of services, as is evident in the dramatic extension of performance frontiers in key areas such as transportation, communication, manufacturing, and health. If technological knowledge can be made explicit it can be legally protected and become an intellectual asset, such as a patent or a copy right. IP can be a powerful source of competitive advantage. In fact, one of the striking features of the service economy is its opening up of opportunities for science-based businesses upstream that aim to make intellectual capital creation their main source of revenue. In turn, downstream companies prioritize investments into market-based assets, like the pharmaceutical industry, that specialize in turning patented ideas and technologies into real-word products (Mock. 2005). Whether IP is owned by a specialized research firm or by the company delivering the final product to their clients, IP can be a powerful source of competitive advantage.

Resource-Based Social Capital: Engaged Employees. People make the crucial difference to any asset and organizations as a whole as people are the key to a firm's level of customer centricity and they are holders of tacit knowledge. In contrast to material or intellectual assets, people have agency as well as human capabilities and traits like empathy, communication, and creativity. A substantial share of such knowledge is tacit and defies encoding and is therefore embedded in the company's people, resources and routines which makes it hard to copy (Pisano and Teece, 2007).

The quality of an organization's people is crucial for its market success and financial 
performance. Employees have the power to breathe life into assets, energize processes, and make the difference by their efforts to understand customer needs and expectations, as well as delivering the performance and productivity that eventually lead to high service quality, customer satisfaction and loyalty (Bowen and Schneider 2014; Wirtz and Jerger 2017; Subramony et al. 2017). However, boundary-spanning frontline jobs are challenging, they often come with role conflict and emotional labour (Wirtz and Jerger, 2017). Successful organizations address those challenges and are committed to the effective management of human resources, including best practices related to recruitment, training, empowerment, service delivery teams, employee motivation, and creating a strong service culture, climate, and effective service leadership (Wirtz and Jerger, 2017). Excellent HR strategies with strong service leadership often result in a sustainable competitive advantage as it seems harder to duplicate high-performing human assets than any other corporate resource (Wirtz and Lovelock, 2016, p. 443).

\section{Platform-Based Assets}

Most basic services are probably as old as humanity. Long before the dawn of the industrial age, people have offered bed and breakfast, transportation, dining, education and much more. What is usually identified as the rise of the service economy does not necessarily indicate revolutionary new types of offerings but a re-organization of value creation processes (Ehret and Wirtz 2010). The rise of infrastructure technologies, namely IT and transportation services offers new means for transforming resources into services. Infrastructure technologies often unlock the physical location of service provision from the location of its use and experience. Such service platforms serve primarily the interaction between resource owners and service users. By offering virtually universal access, platforms drive scale and liquidity through increasing and consolidating relevant markets (Chesbrough 2011; Parker et al. 2016, 2017; Rifkin 2014). 
We define platforms as configurations of assets that connect resource owners with service users. As for resources, we propose three essential types of platform-based assets: (a) Tangible network capital establishing physical connections between resource owners and resource users; (b) Intangible platform assets build liquidity-enabled virtual platforms, and on technology and software, and (c) Social capital formed of social relationships that facilitates interaction and cocreation between key platform stakeholders. We discuss these in turn.

Platform-Based Tangible Capital: Physical Platforms and Critical Mass. Physical network capital establishes physical connections between resource owners and service users. Basic elements of physical network capital are communication networks most notably the internet and other communication interfaces that connect resource owners and service users. Key elements of such interfaces are sensors that provide real-time information about a service, like the operation of a machine or device, as well as actuators that execute an effect directed through communication networks, like the control of a machine or a drone. Not least, physical network capital resides on intelligence units equipped with data storage and computing power for controlling and directing services (Andersson and Mattson, 2015; Ehret and Wirtz, 2017; Geisberg and Broy, 2015).

By opening up almost universal access to resource owners and service users, physical platform capital constituting the physical backbone of the internet has dramatically increased scale and liquidity of services, offering the critical mass justifying investments into innovative service offerings. In the domain of consumer services like accommodation, car sharing or ride haling, the rise of the sharing economy has made this apparent (Chesbrough, 2011).

Let us illustrate the key economic mechanism at work in physical network capital with the example of a prominent industrial service - the "Power-by-the-Hour"-service offered by 
airplane engine manufacturer Rolls Royce (Ehret and Wirtz, 2017). Instead of buying airplane engines, airlines have been shifting to service models by delegating ownership to service manufacturers who earn revenues only for those hours where the airplane is effective in operation. Thereby, airlines shift a substantial share of the financial risk related to the operation of an airplane to the service provider. Relieved from technical operations, airline management can focus on downstream opportunities, exploring the potential for attractive destinations, requirements for customer service, network extension and brand equity. Striving to succeed in attracting and serving passengers, airline managers appreciate shifting some responsibility to as service provider as well offer providers a self-enforcing incentive justifying investments into safety standards and availability of engines. As the service provider, Rolls Royce gets access to a continuous stream of service revenue it has the clout to capture the financial value for effective service operation as well as efficiency improvements.

Physical network assets are key enablers for the "Power-by-the-Hour" service (Ehret and Wirtz, 2017). Sensors provide information that Rolls-Royce transmits in real-time to its groundcontrol centers. Here, Rolls-Royce gathers intelligence, with the potential for early warning of material wear, and indicate maintenance and repair needs. Passengers benefit from enhanced safety, airlines by a more efficient capital use and Rolls Royce enjoys the option on privileged profit opportunities. Not least, the physical network works as the barrier to entry for potential competitors. While there exists a differentiated market for airplane manufacturing services, including airline-owned maintenance and third-party providers, competitors would need to invest into control centers, sensor-equipment, and world-wide communication connections in order to match performance levels offered by Rolls Royce (Smith, 2013). Once in place, competitors would need to learn how to generate intelligence and activate it for service operations. While 
Rolls Royce has been investing in such systems since its pioneering investments in the 1970's (Smith, 2013), it has reached a level of critical mass for capitalizing its services into financial liquidity, that is hard to match by fresh starters. Critical mass acts as an important barrier to entry as competitors would need a global presence to deliver their service at all major airports around the world. Most low-cost competitors simply do not have the volume to allow for a global presence effectively excluding them from this type of business model.

To conclude, physical network capital and critical mass provide the backbone for driving up scale and reaching critical mass for the liquidity for capitalizing investments in services. Companies with a dominant installed base of physical network capital can use it to develop a sustainable competitive advantage.

\section{Platform-Based Intangible Capital: Critical Mass, IP and Platform Software.}

Intangible capital like software, data-bases or methods for data analysis and intelligence is critical for unlocking value from physical information equipment (Chesbrough 2011; Wirtz 2016). Furthermore, physical information networks produce a growing stream of information on economic activities as not only people but a growing range of devices for transportation, manufacturing or household management gets equipped with sensors and actuators and is connected to the Internet (Ehret and Wirtz, 2017). However, this exploding stream of data remains worthless without further analytical tools that generate intelligence and foster novel services. Google provided a pioneering example by developing algorithms that offer pathways for internet advertisers to find matches with valuable information searchers (Schmidt et al. 2014; Varian, 2008). In those pioneering days, information tended to be valueless without appropriate algorithms and analytical tools that foster intelligence. The exponential growth of data has reversed the process: As several algorithms now contain self-optimizing and learning 
capabilities, algorithms are in need of an exponentially accelerating stream of data. Such artificial intelligence provides the backbone for a growing range of service innovations (Glushko and Nomorosa, 2013), like autonomous driving, automatic translation, real-time energy management, or predictive maintenance.

Such algorithms are a key backbone of the intellectual capital embodied in the platform (Azevedo and Weyl, 2016; Brynjolfsson and McAfee, 2014; Ketter et al. 2016). IBM’s Watson program provides a striking example how intellectual platform capital becomes the hub for a boon of service innovations, such as health, smart cities, or smart manufacturing (Hempel, 2013).

Artificial intelligence provides also the intellectual backbone of an emerging new family of industrial services and solutions where platform providers connect real-time operations data with context information for managing, learning, and improving services and solutions. For example, General Electric is using artificial intelligence for smarter management of its power plants by using data on weather, traffic and user patterns for power and network management (Ehret and Wirtz 2017).

\section{Platform-Based Social Capital: Network of Suppliers, Complementors and Partners.}

The social capital of a firm consists of the network of social relationships of a firm (Granovetter, 2005; Florin et al. 2003; Xiong and Bharadwaj, 2011). The extension of physical communication networks has stimulated dramatic shifts in the social capital of organizations, as online social networks cut across both, internal and external organizational boundaries (Huysman and Wuff, 2004; Van den Bulte and Wuyts, 2007).

Building on the ubiquitous access opened by physical networks like the internet, intangible capital provides both, the potential to increase scale for a service for capitalizing service investments, as well as the establishment of service innovations building on new types of 
relationships. By connecting to platforms, asset-owners push their outreach, not unlike manufacturers using distribution channels in industrial economies. Sharing platforms like AirBnB, Uber or Wingly increase the relevant market for both, owners and potential users of facilities or equipment like flats, cars or jets (Chesbrough 2011).

While customer relationships are an essential element of social capital, platforms foster the emergence of novel relationships most notably between owners of facilities such as accommodations, cars or machines, service users, and other complementors such as programmers, or financial service providers that complement towards the service experience of users (Florin et al. 2003; Granovetter 2005; Ndubisi et. al., 2016; Xiong and Bharadwaj 2011). In the context of networked economies, social capital is crucial for mobilizing resources and services beyond the boundaries of the firm, as well as provide the absorptive capacity that enables the firm to capture value (Florin et al. 2003; Xiong and Bharadwaj 2011).

Two- or multi-sided business models are the key where platform providers aim to attract a critical mass of demand for the capitalization of asset-based services (Landsman and Stremersch 2011; Wirtz 2016). Media-businesses developed the blueprint, where media audiences attracted by content provided the critical mass for sponsoring by advertisers. Google translated such models by offering internet-search for free and reach the critical mass for capitalizing search sponsorships (Schmidt et al. 2014; Wirtz, 2016). Platforms work as critical backbones for developing new markets. Consider Etsy, which originally worked as an online sales channels for hobbyist and micro-entrepreneurs for commercializing self-designed accessories. Etsy's management soon had to learn that the restriction of single items offered by designers puts a barrier on growth. By connecting designers to contract manufacturers, Etsy opened new channels for small batches of attractive designs that offered growth opportunities 
(Ehret and Wirtz 2017).

To conclude, social capital offers firms the lever for scaling up relevant markets, reaching critical mass for capitalizing investments, therefore, driving liquidity. Owners of platforms endowed with high social capital control a strong lever for sustaining competitive advantage.

\section{Market-Based Assets}

Market based assets empower a firm to explore and exploit opportunities related to customer needs. In market economies, value-in-use is the ultimate yardstick for economic activity where resources need to prove their worth (Macdonald et al. 2016; Menger 1981; Vargo and Lusch 2004). Market-based assets connect businesses to customers and enable businesses to explore customer needs, design service offerings and specify service contracts for effective service delivery. Essential market-based assets are the physical capital constituting the points-ofcustomer interaction, intellectual capital underlying brands and trademarks, and social capital constituting customer equity. We discuss these in turn.

Market-Based Tangible Capital: Points of Customer Interaction. Service demand emerges through interaction between customers and providers, revealing customer needs, specifying requirements and creating orders (Grönroos, 2012; Vargo and Lusch, 2004). The history of the retailing industry provides an intriguing case. Retailers emerged as the Trojan horse that nested services in the context of goods-dominant industries. Retailers established themselves by taking a crucial role for manufacturers, extending market reach, increasing economies of scale and thereby competitiveness of manufacturers. With the maturing of the manufacturing base, retailers have been gaining a pole position at the front-end of value chains, getting insights into customer behavior and substantial clout for affecting the fortunes of manufacturer brands (Frazier and Summer 1984; French and Raven 1959; Hunt 2015; Lusch 
1976). Powerful retailers like Walmart have been pushing leading consumer brand manufacturers like Procter \& Gamble to place heavy investments into innovations in order to stave off commoditization of their brands and regain attractiveness (Huston and Sakkab 2006).

At the high-end of the market, manufacturers try to regain strength by maintaining their own exclusive retail channels, allowing them to get direct customer contact and shape customer experiences and learning. For example, Burberry used a retailing strategy by investing in a global retailing network as a key element in the recent relaunch of its fashion brand built around its classic trench coat (Ahrendts 2013). A growing range of high-end and luxury manufacturers like Tesla in electric cars (Hull 2015), Apple in computer electronics (Cojet 2011) or Nike in sports fashion and Luis Vuitton in fashion, is investing in its own retailing facilities in order to shape the experience and gate the customer. There is a lot of value in being able to control the POS (i.e., what is presented to potential customers) and the customer interaction ("I can recommend...).

To conclude, owning points of customer interaction and access constitute powerful assets opening pathways to customers, exploring customer needs and generate demand that strengthens the power of their owners within the service value chain.

Market-Based Intangible Capital: Virtual POS, Communications Channels, and Brands, Trademarks and Loyalty Programs. In a service economy, points of customer interaction have become increasingly virtual (e.g., websites and apps) and constitute the front ends of the service value chain, sensing customer needs, identifying potential service offerings, specifying potential third-party orders and not least, handling transactions including upselling and cross-selling, and financial payments (Agrawal and Schmidt 2003; Evans et al. 1999). Virtual POS command the same power in value chains as do physical ones and are the 
battleground in many industries (e.g., Amazon, Uber, and AirBnB's dominance in their industries are all based on virtual POSs and communications channels).

In addition to channels, brands and trademarks can be powerful market-based assets. Prior to the purchase, value propositions exist as mere promises of companies or expectations of customers. This puts brands on the center-stage of service businesses. Brands signal their capabilities and benefits, and show commitment and accountability (Chang and Liu 2009).

We find striking evidence in many industries like hotels (O’Neill and Matilla 2006), retailing, or integrated health systems (Zismer 2013) where brand owners govern the front-end of the service value chain, shaping expectations and perception of clients, while outsourced specialized service providers manage facilities, property, and capabilities for service delivery. Brands and their related brand equity build customer equity and work as the levers for conveying quality into financial value and therefore are a pillar for the pole position in the service value chain (Aaker and Jacobson, 1994; Rao, et al. 2004). Once a provider has succeeded to establish a brand, it is hard to copy (Bronnenberg et al. 2009, DuWors and Haines, 1990: Yeoman et al. 2005).

Not least, in complex services like system-technologies or knowledge-intensive services, brands hold providers accountable (Aaker and Jacobson 2001). With their brand image, brand owners offer their clients a self-enforcing mechanism, as opportunistic or unethical actions of providers jeopardize brand equity. Positive brand image shields providers of complex services against technically competent competitors who will need to build up brand equity to enter the evoked set of potential clients (Corkindale and Belder 2009).

To conclude, brand equity orchestrates client expectations with providers’ brand personality and is the key to creating the trust basis enabling service transactions and mutual co- 
creation. By building brands providers create a unique, sustainable competitive advantage that is hard to copy and constitutes the pole position at the value chain.

Market-Based Social Capital: Customer Equity, Trust, and Goodwill. Customer equity is a strong source of competitive advantage. Customer equity builds on customer relationships which constitute the market dimension of the social capital of a firm. Customer equity is a powerful asset connecting its owners to their customers, frequently providing a stable cash flow from a firm’s customer base, effectively delivering services through customer co-creation and providing privileged insights into customer needs. Financially, customer revenues constitute the top-line of the income statement. Customer relationship management researchers reflect this when they define customer equity as "the total of the discounted lifetime values of all of its customers” (Rust, Lemon and Zeithaml, 2000, see also Kumar and Reinartz, 2016).

Customers are also indispensable in the value creation process as they co-create value with the firm and their perception ultimately determine the value of product (Kumar and Reinartz 2016; Macdonald et al. 2016). Furthermore, besides actual transactions, customers offer value for the firm trough their engagement (Rust et al. 2000; Kumar and Reinartz, 2016). They affect the firm's fortunes through word-of-mouth, work as ambassadors for the firm through referral programs and referrals on social networks and in brand communities (Leone et al., 2006; Rego et al., 2009; Raithel et al., 2016; Wirtz et al., 2014) and hold valuable knowledge through their user experience of the firm's offerings.

Over time, customers can be a source of innovation and future products. Products can be copied and re-engineered by competitors and thereby will commoditize offerings and drive down profits. Well-established customer relationships provide knowledge and insights into user contexts and future needs, offering companies with opportunities to learn customer requirements 
as a lever for differentiating future offerings (Haenlein et al. 2006; Rust et al. 2000).

In short, relationships emerge through recurring interactions, driven by satisfaction, service quality and trust in competencies and good-will of providers (Morgan and Hunt, 1994; Ndubisi et al. 2016). While customer equity is crucial for converting resources into financial performance, it is hard to build and copy - driving the asset-character of customer equity.

\section{Employing Assets for Capturing Value Through Superior Organizational Capabilities}

While this article focuses on which assets a firm should assume ownership in to allow capturing value, this discussion would be incomplete without considering the glue, the organizational capabilities, that hold them together and effectively deploy the assets discussed so far. Specifically, we identified four important organizational capabilities of asset integration that are independent of asset ownership but effectively link owned and outsources assets, capabilities, and processes to value creation and we proffer that these can also allow a firm to capture value. They are (1) a coherent business model itself that designs the architecture and "Gestalt" of value creation; (2) a customer-centric culture and a climate for service; (3) sustained innovation capabilities, and (4) the effective management of a tightly integrated web of processes and activities.

Business Models: Shaping the "Gestalt” of Asset Configurations. Business models build a unique constellation of assets that together are hard to copy (Porter 1980). Business models build on key elements of which four are of particular relevance for services: (1) Establishing connections between resource and service markets; (2) identifying value propositions for individual firms; (3) identifying a value appropriation mechanism; and (4) identifying a network of collaborating firms or stakeholders for complementing the firm's value proposition into a compelling solution (Chesbrough 2011; Ehret et al. 2013; Osterwalder and Pigneur 2005; Wirtz 
2016; Zott and Amit 2008). Here, business models provide the basis for designing an architecture of service assets and identify the "Gestalt" of their configuration.

Customer-Centric Organizational Culture and Climate for Service. While assets do not drive agency, people do. Because both, clients and providers co-create services, providers need to develop processes for the effective interaction of the service partners. People and their embedding in organizational cultures, as well as service processes, are key conditions for transforming assets into value as well as differentiate the service firm and navigate it towards competitive advantage. Employees offer the key to service excellence to the extent that they develop a shared sense of service quality, not least the policies, practices and procedures and their impact on service quality (Bowen and Schneider, 2014). By creating a favorable "service climate” firms shape their unique competitive position (Bowen and Schneider, 2014). Service climate builds on shared perceptions, values, norms, and working styles (Bowen and Schneider, 2014). Employees and service climate can shape in a unique and idiosyncratic way how the service organization differentiates its assets and resources. For example, Amazon, Vanguard and Singapore Airlines developed a competitive advantage due to the superior integration of the conflicting goals of service excellence and cost-effectiveness (Wirtz and Zeithaml 2018).

Serial Innovation. In hypercompetitive industries, an organizational capability of innovating faster and better (even when these innovations are copied quickly by competition), can become a competitive advantage. Some organizations can be an innovation leader in their industry over prolonged periods of time (i.e. are serial innovators; Hamel, 2006). Here, sustained innovation is a firm's capability to generate a stream of industry-leading innovations (i.e. multiple new products and services, encompassing both incremental and radical innovations). Innovation climate (i.e. leadership and innovative culture), human capital (i.e. recruitment, 
training and development and engagement and incentives), and resource configurations (i.e. structures, systems, and processes) were advanced as key foundations for success (Tuzovic, Wirtz, and Heracleous, 2018).

Integrated Web of Processes and Activities. The service process is the moment of truth for the contribution of any asset for its contribution towards value creation and capture. So far, we have mainly discussed the potential offered by assets. But left on their own premises, assets remain idle and will devaluate over time. Action drives value creation and firms can differentiate their assets through processes and activities. As Porter (1996) puts it: “Competitors can quickly imitate management techniques, new technologies, input improvements, and superior ways of meeting customer needs." (Porter, HBR, 1996, p. 63). Rather, it is the "fit, whereby the whole matters more than any individual part. Competitive advantage grows out of the entire system of activities.” (Porter 1996, p. 63). Services offer strong opportunities for creating unique webs and systems of processes and activities (Wirtz and Lovelock 2017).

First, as customer's perceptions drive service quality, service firms willingly or unwillingly differentiate themselves when performing with customers. Showing service effort and creating customer delight paths the way towards a unique image of the firm. Showing empathy and interacting with customers, empowers firms to differentiate themselves.

Second, services reside on multiple sets of activities, integrating resources and using technologies guided by people who show the potential for understanding and interacting with customers. Thus, service organizations have a broad spectrum of choices for designing processes and orchestrate them towards unique service experiences. Such processes reside on organic ecosystems rather than vertical value chains. Singapore Airlines provides a telling example, as it links its service culture and climate for a continuous learning and adaption of processes and 
activities (Heracleous and Wirtz 2010).

\section{Managerial Implications}

Assets offer firms entry gates to profit opportunities but can turn easily into liabilities. Thus, on the path towards sustainable competitive advantage managers need to understand the relation of assets with opportunities. In our chapter, we identify three major domains as sources for opportunities which call for particular asset-types. Resource-based assets offer unique capabilities and capacity fostering service performance. Platform-based assets drive competitive advantage through service innovation, by enabling new connections between the resource base and service users. Platform-based assets provide the crucial means for driving scale, liquidity and critical mass for capitalizing investments into services. Market-based assets open pathways for companies to exploration and exploitation for unmet demand by potential service clients, namely through points of customer interaction, brand equity, customer equity.

The Case for Selective Ownership Approaches. The key implication for management is the urge for selective approaches to asset-ownership. Management concepts like outsourcing or non-ownership have raised the awareness of alternatives to ownership as well as questioning the scope of ownership. Despite the rise of effective alternatives, ownership of strategic assets remains a key pillar for differentiation and capturing profits. Thus, managers should strive for selective ownership rather than simple non-ownership approaches. As a general rule, managers should identify, establish and nurture the key assets as sources of their competitive advantage, and complement these with external services offered by excelling third-party service providers. Key assets should be tied to market opportunities. Thus, managers need a dynamic approach towards asset ownership as the market environment can shift in favor of particular kinds of assets while commoditizing others. For example, technology developments can raise the attractiveness 
of ownership of assets. In the car industry, batteries used to be outsourced to component suppliers, while they have now reached the center stage of in-house development and even manufacturing. The rise of artificial or augmented intelligence has been strengthening the urge of Apple to grow its scope its own processor, which it had outsourced for a substantial time.

Asset Configurations and the Case for Business Services. Critical assets can be found on all stages along the value chain. Thus, managers should keep a clear mind and open view especially on assets that are positioned in seemingly distant areas in the value chain. Especially companies that have a reputation for strong outsourcing maintain a variety of critical assets along each step of the value chain in-house. For example, Nike might have a justified reputation for extreme outsourcing but owns critical assets on each stage of the value chain, including resource markets, for example, the design of critical materials and textiles, in addition to signature shops and internet-sales platforms besides investing in one of the most valuable sports and fashion brands.

In order to be valuable, assets need to be unique. Ownership is the main tool that empowers managers to establish and protect distinctive resource combinations. At the same time, resources need to be conversible, urging managers to establish and maintain interfaces downstream with customers and marketing channels. These conditions of uniqueness and conversibility of resources push companies to invest into configurations of assets where some assets provide unique sources of value while others might path ways towards customers.

In that regard, platforms offer a useful metaphor for the business model design of almost any business. As most businesses start from stronger positions either in the downstream product or upstream resource markets, strategic and attractive positions are intrinsically linked to both. Even when companies feel far off world-market dominating positions like Qualcomm, Google or 
Apple, they face similar challenges on smaller levels in different contexts: How can they provide unique value and maintain a strong bargaining position with their customers? Here competitive advantages build on strong positions in both up- and downstream markets.

\section{Research Opportunities}

In our chapter, we provide a starting point by identifying the roles of assets in the process of exploring and exploiting business opportunities. In the following section, we identify potentially interesting research opportunities.

Selective Asset Ownership. The non-ownership perspective has provided a useful and theoretically well-founded criterion for the definition of services (Lovelock and Gummesson 2004). The rise of the service economy goes in hand with a growing range of business services that allow organizations to outsource an ever-increasing rage of assets and activities (Ehret and Wirtz 2010). In order to exploit the full potential of this approach, service research needs to look at the flip-side of non-ownership, that is, the role of asset ownership in the service economy. The hidden assumption underlying the viability of non-ownership service business models holds that there exists an actor who takes-on ownership of the assets that are used for service-delivery.

To some extent, non-ownership provides business opportunities to service providers who are willing and capable of taking on ownership deemed of little value by other participants in the value creation process. Thus, service research needs concepts that reflect the full implications following from selective ownership approaches. What conditions, capabilities and resources empower service providers to handle assets that fall out of the scope of their potential clients? Ownership offers crucial incentives for companies to focus on specific domains of value creation, mainly by vesting power towards service providers and offering them profit opportunities. Still, the question remains, what factors render an asset valuable for one firm, 
while it seems to have become of little value to others.

Property-rights theory offers a valid starting point for understanding such phenomena in static positions by looking at the transaction cost implications of asset specificity, rendering ownership valuable for companies with comparable higher opportunity costs, while favoring service-sourcing with lower opportunity costs (Barzel 1997; Ehret and Wirtz 2010; Grossman and Hart 1986). As we show in our discussion, such perspectives are snapshots of dynamic processes. In the face of increasing competitive pressure, both researchers as well as managers, need an understanding of dynamic factors that prior to the specificity and opportunity costs of assets beyond the transaction cost implications. This is the background of the growing efforts in entrepreneurship research as well as in business model design (Chesbrough 2011; Zott and Amit 2008).

Asset Configuration. Conceptual reflections regarding asset ownership reveal a greenfield of research opportunities for service research. Extant empirical research has remained almost blind on the role of assets in service provision. We need a better understanding of the asset configurations owned by organizations. For example, the combination of intangible assets like brands and platforms with tangible assets like technological equipment and real estate. Such typologies of configurations would mark the first step in systemizing our understanding of antecedents that motivate companies and their stakeholder that drive the emergence of such ownership structures. Ultimately, we need a better understanding of how particular asset configurations affect the performance of firms, the quality of their services, as well as their economic and social value on a macro-level.

Real-Option Value of Nonownership. Nonownership decisions build on the asymmetric perception of uncertainties. Nonownership service providers embrace uncertainties that their 
clients loaf and are willing to pay service fees for discarding them. Arguably, asymmetric uncertainty is a key condition and source of nonownership value, if not service value in general. From a financial perspective, service contracts share some features with financial options. Service clients enjoy the right to benefits of a service without the obligation to bear the downsides. Thus, service clients enjoy benefits quite comparable to those of option holders who hold the right, but not the obligation, to sell a stock at a certain price at a certain time. Like option holders only risk the option price, service clients limit the financial risk to the service fee (McGrath et al. 2004).

Service research has not yet reflected the potential offered by real-options for the systematic valuation of non-ownership services and services in general. While research still faces methodological challenges in real-option valuation, researchers are making progress and can look forward to a growing stream of data on financial valuation and the environment of services (Taleb 2012).

Core Competencies, Service Culture and Asset Creation. We have stressed the managerial challenge in matching assets and with a firm's capabilities and culture. However, we have scant evidence that competencies and the culture of a firm shape the types of assets employees develop and managers seek to control. Companies cultivating innovative cultures tend to develop higher shares of intellectual assets. We have reasons to assume that assets hold the potential to work as a strategic repository for values, knowledge, and competencies cultivated within a firm. These open up opportunities for research to explore systematic trajectories between corporate cultures and the acquisition, creation, and management of strategic assets within a firm.

\section{Conclusions}


In advanced service economies, almost any activity, skill, and asset can be bought on competitive markets, making it increasingly difficult to build competitive advantage on any of those inputs. This emergence of service B2B business models reflects the pressure of hypercompetition forcing companies to focus ownership on those assets that offer them the highest potential for value appropriation while delegating ownership of non-essential assets to service providers. Therefore, firms have to carefully decide what to own in order to capture value. That is, firms have to explore what types of assets can add value to their customers and at the same time are difficult or illegal to copy by competition. We identified key asset categories that potentially allow a firm to appropriate value and argue that each can take the form of tangible, intangible and social capital. The three asset types and their three manifestations are integrated into a framework for an asset typology (see Figure 2). In addition, we proffer four organizational capabilities of asset integration that potentially also can form the base for an organization's competitive advantage. We hope that this conceptual chapter will lead to further investigation into the intriguing question of the role of asset ownership in capturing value in modern, highly specialized service economies. 
Figure 1: Value Chain in a Modern Service Economy Where Most Assets, Activities, and Skills can be Outsourced

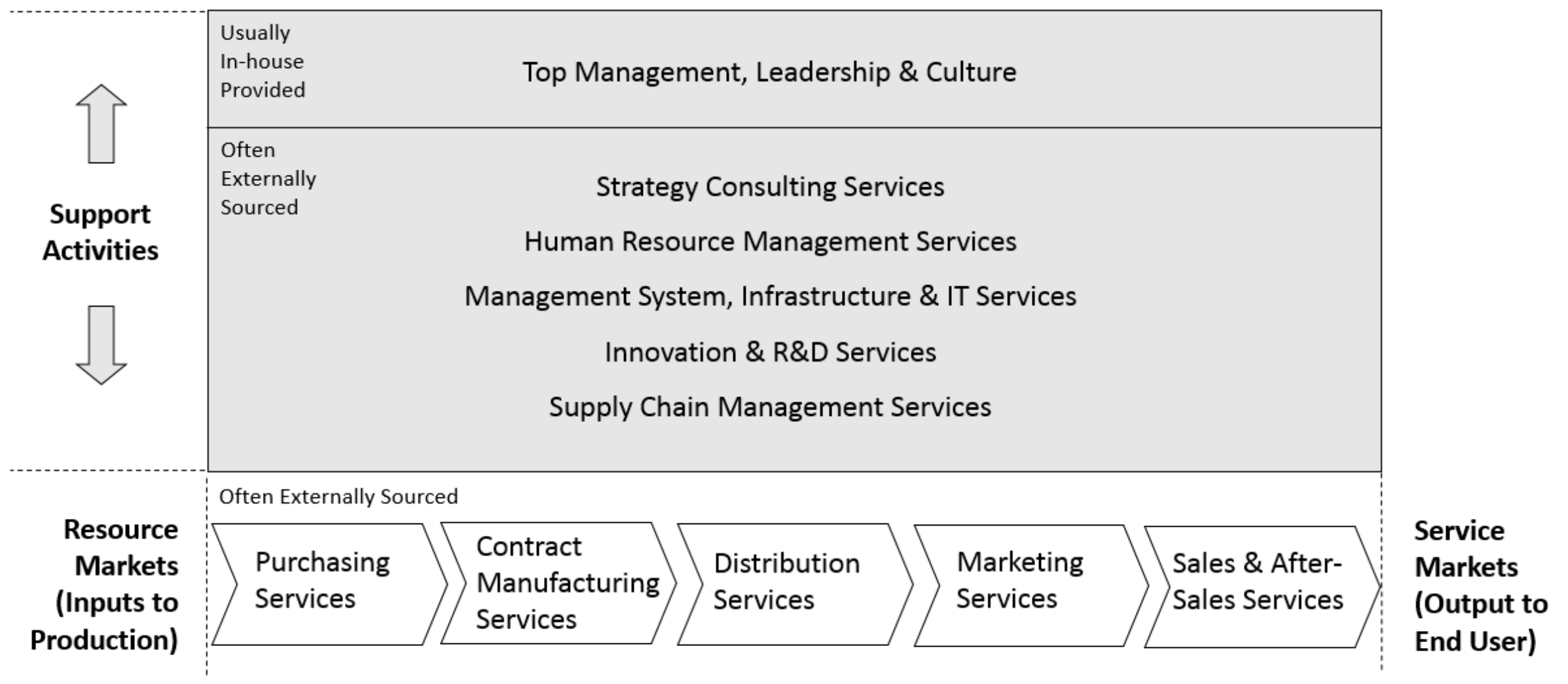


Figure 2: Assets and Capabilities that Enable Capturing Value in the Service Economy

\begin{tabular}{|c|c|c|c|}
\hline & $\begin{array}{c}\text { Resource-Based } \\
\text { Assets }\end{array}$ & $\begin{array}{c}\text { Platform-Based } \\
\text { Assets }\end{array}$ & $\begin{array}{c}\text { Market-Based } \\
\text { Assets }\end{array}$ \\
\hline $\begin{array}{l}\text { Tangible } \\
\text { Capital } \\
\text { (has a physical } \\
\text { manifestation) }\end{array}$ & $\begin{array}{l}\text { - } \text { Equipment (e.g., } \\
\text { specialized machines) } \\
\text { - Systems (e.g., smart } \\
\text { systems) } \\
\text { - Facilities (e.g., } \\
\text { supplier parks and } \\
\text { integrated campuses) }\end{array}$ & $\begin{array}{l}\text { - Physical platform asset, incl. } \\
\text { physical networks, intelligence } \\
\text { units, computing sensors and } \\
\text { actuators } \\
\text { - Critical mass or liquidity-enabled } \\
\text { physical platforms (e.g., a large } \\
\text { installed base) }\end{array}$ & $\begin{array}{l}\text { - Physical points-of-sale (POS) } \\
\text { (e.g., retail and sales networks; } \\
\text { customer contact centers) }\end{array}$ \\
\hline $\begin{array}{l}\text { Intangible } \\
\text { Capital } \\
\text { (has a virtual } \\
\text { manifestation } \\
\text { that can be } \\
\text { codified } \\
\text { and legally } \\
\text { protected) }\end{array}$ & $\begin{array}{l}\text { Intellectual property } \\
\text { related to } \\
\text { manufacturing, incl. } \\
\text { patents and copyrights }\end{array}$ & $\begin{array}{l}\text { - Critical mass or liquidity-enabled } \\
\text { virtual platforms (e.g., an } \\
\text { electronic market place) } \\
\text { - Intellectual property related to } \\
\text { platforms, incl. patents and } \\
\text { copyrights on platform } \\
\text { technology and software }\end{array}$ & $\begin{array}{l}\text { - Brands and related band equity } \\
\text { - Trademarks (e.g., a logo or specific design) } \\
\text { - Customer databases and loyalty programs } \\
\text { - Virtual POS, incl. websites, apps } \\
\text { - Other facilities for customer interaction, incl. websites, } \\
\text { apps, social media sites, and other communications } \\
\text { channels (e.g., online brand communities) } \\
\text { - Access to distribution networks (e.g., exclusive } \\
\text { retailers, store listings) }\end{array}$ \\
\hline \multirow[t]{2}{*}{$\begin{array}{l}\text { Social } \\
\text { Capital } \\
\text { (embedded in } \\
\text { people's minds; } \\
\text { cannot be legally } \\
\text { protected) }\end{array}$} & $\begin{array}{l}\text { Trust, goodwill and } \\
\text { engagement of } \\
\text { employees }\end{array}$ & $\begin{array}{l}\text { Trust, goodwill and engagement } \\
\text { of stakeholders, incl. suppliers, } \\
\text { complementors, and partners. }\end{array}$ & $\begin{array}{l}\text { - Customer equity (i.e., the life-time value of } \\
\text { the customer base) } \\
\text { - Trust, goodwill, and engagement of } \\
\text { customers (incl. brand communities) and of } \\
\text { other market-relevant stakeholders (incl. } \\
\text { media and society at large) }\end{array}$ \\
\hline & \multicolumn{3}{|c|}{$\begin{array}{l}\text { Organizational Capabilities } \\
\text { - Business Models: "Gestalt" of Asset Configurations } \\
\text { - Customer-Centric Culture and a Climate for Service } \\
\text { - Innovation } \\
\text { - Integrated Web of Processes and Activities }\end{array}$} \\
\hline
\end{tabular}

Adapted from Wirtz and Ehret 2017 


\section{References}

Aaker, D.A. \& Jacobson, R. (1994). "The Financial Information Content of Perceived Quality", Journal of Marketing Research, 31(2), pp. 191-201.

Aaker, D.A. \& Jacobson, R. (2001). "The Value Relevance of Brand Attitude in HighTechnology Markets", Journal of Marketing Research, 38(4), pp. 485-493.

Agrawal, M.L. \& Schmidt, M. (2003). "Listening Quality of the Point of Service Personnel (Psps) as Impulse Trigger in Service Purchase: a Research Framework", Journal of Services Research, 3(1), pp. 29.

Ahrendts, A. (2013). "Burberry's CEO on Turning an Aging British Icon into a Global Luxury Brand", Harvard Business Review, 91(1), pp. 39-42.

Amit, R. \& Schoemaker, P.J.H. (1993). "Strategic Assets and Organizational Rent", Strategic Management Journal, 14(1), pp. 33-46.

Amit, R. \& Zott, C. (2001). "Value Creation in E-Business", Strategic Management Journal, 22(6), pp. 493.

Azevedo, E.M. \& Glen Weyl, E. (2016). "Matching markets in the digital age", Science, 352(6289), pp. 1056-1057.

Barzel, Y. 1997, Economic analysis of property rights, 2nd edn, Cambridge University Press, Cambridge.

Bowen, D.E. \& Schneider, B. (2014). "A Service Climate Synthesis and Future Research Agenda", Journal of Service Research, 17(1), pp. 5-22.

Bronnenberg, B.J., Dhar, S.K. \& Dubé, J.H. (2009). "Brand History, Geography, and the Persistence of Brand Shares", Journal of Political Economy, 117(1), pp. 87-115.

Brynjolfsson, E. \& MacAfee, A. (2014). The second machine age: work, progress, and prosperity in a time of brilliant technologies, first ed., Norton, New York.

Buera, F.J. \& Kaboski, J.P. (2012). "The Rise of the Service Economy", American Economic Review, 102(6), pp. 2540-2569.

Chang, H.H. \& Liu, Y.M. (2009). "The impact of brand equity on brand preference and purchase intentions in the service industries", Service Industries Journal, 29(12), pp. 1687-1706.

Chesbrough, H.W. 2011, Open services innovation: rethinking your business to grow and compete in a new era, Jossey-Bass, San Francisco, Calif.

Corkindale, D. \& Belder, M. (2009). "Corporate brand reputation and the adoption of innovations", Journal of Product \& Brand Management, 18(4), pp. 242-250.

DuWors Jr., R.E. \& Haines Jr., G.H. (1990). "Event History Analysis Measures of Brand Loyalty", Journal of Marketing Research, 27(4), pp. 485-493.

Ehret, M., Kashyap, V. \& Wirtz, J. (2013). "Business models: Impact on business markets and opportunities for marketing research", Industrial Marketing Management, 42(5), pp. 649-655.

Ehret, M. \& Wirtz, J. (2010). "Division of Labor between Firms: Business Services, NonOwnership-Value and the Rise of the Service Economy", Service Science, 2(3), pp. 136145. 
Ehret, M. \& Wirtz, J. (2017). "Unlocking value from machines: business models and the industrial internet of things", Journal of Marketing Management, 33(1), pp. 111-130.

Ehret, M. \& Wirtz, J. (2018), “Ownership of Cocreation Assets: Driving B2B Value Propositions in the Service Economy,” Journal of Creating Value, forthcoming.

Evans, K.R., Arnold, T.J. \& Grant, J.A. (1999). "Combining Service and Sales at the Point of Customer Contact: A Retail Banking Example", Journal of Service Research, 2(1), pp. 34.

Florin, J., Lubatkin, M. \& Schulze, W. (2003). "A Social Capital Model of High-Growth Ventures", Academy of Management Journal, 46(3), pp. 374-384.

Frazier, G.L. \& Summers, J.O. (1984). "Interfirm Influence Strategies and Their Applications within Distribution Channels", Journal of Marketing, 48(3), pp. 43-55.

Glushko, R.J. \& Nomorosa, K.J. (2013). "Substituting Information for Interaction: A Framework for Personalization in Service Encounters and Service Systems", Journal of Service Research, 16(1), pp. 21-38.

Granovetter, M. (2005). "The Impact of Social Structure on Economic Outcomes", Journal of Economic Perspectives, 19(1), pp. 33-50.

Grönroos, C. (2012). "Conceptualising value co-creation: A journey to the 1970s and back to the future", Journal of Marketing Management, 28(13-14), pp. 1520-1534.

Grossman, S.J. \& Hart, O.D. (1986). "The Costs and Benefits of Ownership: A Theory of Vertical and Lateral Integration", Journal of Political Economy, 94(4), pp. 691-719.

Haenlein, M., Kaplan, A.M. \& Schoder, D. (2006). "Valuing the Real Option of Abandoning Unprofitable Customers When Calculating Customer Lifetime Value", Journal of Marketing, 70(3), pp. 5-20.

Hempel, J. (2013). "IBM's Massive Bet on Watson", Fortune, 168(6), pp. 80.

Heracleous, L. \& Wirtz, J. (2010). "Singapore Airlines' Balancing Act", Harvard Business Review, 88(7), pp. 145-149.

Hull, D. (2015). "For Tesla, Stores Are Classrooms, Too", Bloomberg Businessweek, (4440), pp. 20-21.

Hunt, S.D. (2015). "The bases of power approach to channel relationships: has marketing's scholarship been misguided?", Journal of Marketing Management, 31(7-8), pp. 747764.

Huston, L. \& Sakkab, N. (2006). "Connect and Develop ", Harvard Business Review, 84(3), pp. 58-66.

Huysman, M. \& Wulf, V. (2004). Social capital and information technology, MIT Press, Cambridge, Mass.

Ketter, W., Peters, M., Collins, J. \& Gupta, A. (2016). "Competitive Benchmarking: an is Research Approach to Address Wicked Problems with Big Data and Analytics", MIS Quarterly, 40(4), pp. 1057-1089.

Kirzner, I.M. (1997). "Entrepreneurial Discovery and the Competitive Market Process: An Austrian Approach", Journal of Economic Literature, 35(1), pp. 60-85.

Kumar, V. \& Reinartz, W. (2016). "Creating Enduring Customer Value", Journal of Marketing, 80(6), pp. 36-68. 
Landsman, V. \& Stremersch, S. (2011). "Multihoming in Two-Sided Markets: An Empirical Inquiry in the Video Game Console Industry", Journal of Marketing, 75(6), pp. 39-54.

Leone, R.P., Rao, V.R., Keller, K.L., Luo, A.M., McAlister, L. \& Srivastava, R. (2006). "Linking Brand Equity to Customer Equity", Journal of Service Research, 9(2), pp. 125-138.

Lewin, P. (1999), Capital in disequilibrium: the role of capital in a changing world, Routledge, London.

Lovelock, C. \& Gummesson, E. (2004). "Whither Services Marketing?: In Search of a New Paradigm and Fresh Perspectives", Journal of Service Research, 7(1), pp. 20-41.

Lusch, R.F. (1976). "Sources of Power: Their Impact on Intrachannel Conflict", Journal of Marketing Research, 13(4), pp. 382-390.

MacDonald, E.K., Kleinaltenkamp, M. \& Wilson, H.N. (2016). "How Business Customers Judge Solutions: Solution Quality and Value in Use", Journal of Marketing, 80(3), pp. 96-120.

McGrath, R.G., Ferrier, W.J. \& Mendelow, A.L. (2004). "Real Options as Engines of Choice and Heterogeneity", Academy of Management Review, 29(1), pp. 86-101.

Menger, C. 1981, Principles of economics, New York University Press, New York; London.

Mock, D. 2005, The Qualcomm Equation - How a Fledgling Telecom Company Forged a new Path to Big Profits and Market Dominance. Amacom, New York.

Morgan, R.M. \& Hunt, S.D. (1994). "The Commitment-Trust Theory of Relationship Marketing", Journal of Marketing, 58(3), pp. 20

Ndubisi, O.N., Ehret, M., \& Wirtz, J. (2016), "Relational Governance Mechanisms and Uncertainties in Nonownership Services”, Psychology and Marketing, 33(4), pp. 250266.

OECD (ed) 2007, Staying Competitive in the Global Economy: Moving Up the Value Chain, OECD, Paris.

Osterwalder, A. \& Pigneur, Y. (2005). "Clarifying Business Models: Origins, Present, and Future of the Concept", Communications of AIS, 16, pp. 1-25

Parker, G.G., Alstyne, M.W.V. \& Choudary, S.P. 2016, Platform revolution: how networked markets are transforming the economy - and how to make them work for you, First Edition edn, Norton, New York.

Parker, G., Van Alstyne, M. \& Jiang, X. (2017). "Platform Ecosystems: how Developers Invert the Firm", MIS Quarterly, 41(1), pp. 255-A4.

Penrose, E.T. 1959, The theory of the growth of the firm, Blackwell, London.

Pisano, G.P. \& Teece, D.J. (2007). "How to Capture Value from Innovation: Shaping Intellectual Property and Industry Architecture", California Management Review, 50(1), pp. 278-296.

Porter, M.E. (1996), "What Is Strategy?", Harvard Business Review, 74(6), pp. 61-78.

Porter, M.E. (1980), Competitive Strategy: Techniques for Analyzing Industries and Competitors, Free Press, New York.

Quinn, J.B. (1992), Intelligent enterprise: a knowledge and service based paradigm for industry. Maxwell Macmillan: Maxwell Macmillan International, Free Press. 
Raithel, S., Taylor, C.R. \& Hock, S.J. (2016). "Are Super Bowl ads a super waste of money? Examining the intermediary roles of customer-based brand equity and customer equity effects", Journal of Business Research, 69(9), pp. 3788-3794.

Rao, V.R., Agarwal, M.K. \& Dahlhoff, D. (2004). "How Is Manifest Branding Strategy Related to the Intangible Value of a Corporation?", Journal of Marketing, 68(4), pp. 126-141.

Rego, L.L., Billett, M.T. \& Morgan, N.A. (2009). "Consumer-Based Brand Equity and Firm Risk", Journal of Marketing, 73(6), pp. 47-60.

Rifkin, J. (2014). The Zero Marginal Cost Society: The Internet of Things, the Collaborative Commons, and the Eclipse of Capitalism, Palgrave MacMillan, New York.

Rust, R.T., Ambler, T., Carpenter, G.S., Kumar, V. \& Srivastava, R.K. (2004). "Measuring Marketing Productivity: Current Knowledge and Future Directions", Journal of Marketing, 68(4), pp. 76-89.

Rust, R.T., Lemon, K.N. \& Zeithaml, V.A. (2000). "Return on Marketing: Using Customer Equity To Focus Marketing Strategy”, Journal of Marketing, 68(1), pp. 109-127

Schmidt, E., Rosenberg, J. \& Eagle, A. (2014), How Google Works, John Murray, London.

Shane, S. \& Venkataraman, S. (2000). "The Promise of Entrepreneurship as a Field of Research", Academy of Management Review, 25(1), pp. 217-226.

Stabell, C.В. \& Fjeldstad, Ø.D. (1998). "Configuring value for competitive advantage: On chains, shops, and networks", Strategic Management Journal, 19(5), pp. 413.

Taleb, N. (2012). Antifragile: how to live in a world we don't understand, Allen Lane, London.

Triplett, J.E. \& Bosworth, B.P. (2003). "Productivity Measurement Issues in Services Industries: "Baumol's Disease" Has Been Cured", Economic Policy Review, 9(3), pp. 23-33.

Varian, H.R. (2008). "Designing the Perfect Auction", Communications of the ACM, 51(8), pp. 9-11.

Wernerfelt, B. (1984). "A Resource-based View of the Firm", Strategic Management Journal, 5(2), pp. 171-180.

Wirtz, B. 2016, Business Model Management: Design Process Instruments, 2nd edition edn, German University of Administrative Science, Speyer.

Wirtz, J. \& Ehret, M. (2017), “Capturing Value in the Service Economy”, Journal of Service Management Research, 1(1), pp. 22 - 38.

Wirtz, J. \& Jerger, C. (2017), "Managing service employees: literature review, expert opinions, and research directions", Service Industries Journal, 36(15), pp. 757-788.

Wirtz, J. \& Lovelock C. (2016), Services Marketing: People, Technology, Strategy. $8^{\text {th }}$ ed., New Jersey: World Scientific

Wirtz, J. \& Zeithaml, V. “Cost-Effective Service Excellence”, Journal of the Academy of Marketing Science. 46(1), pp. 59-80.

Wirtz, J., Tuzovic, S. \& Ehret, M. (2015), “Global Business Services: Increasing Specialization and Integration of the World Economy as Drivers of Economic Growth," Journal of Service Management, 26(4), pp. 565-587. 
Wittkowski, K., Moeller, S. \& Wirtz, J. (2013). "Firms’ Intentions to Use Nonownership Services", Journal of Service Research, 16(2), pp. 171-185.

Woelfl, A. 2005, "The Service Economy in OECD countries" in Enhancing the Productivity of the Service Sector, ed. OECD, OECD, Paris, pp. 27-63.

Worm, S., Bharadwaj, S., Ulaga, W. \& Reinartz, W. (2017). "When and why do customer solutions pay off in business markets?", Journal of the Academy of Marketing Science, 45(4), pp. 490-512.

Xiong, G. \& Bharadwaj, S. (2011). "Social Capital of Young Technology Firms and Their IPO Values: The Complementary Role of Relevant Absorptive Capacity", Journal of Marketing, 75(6), pp. 87-104.

Yeoman, I., Durie, A., McMahon-Beattie, U. \& Palmer, A. (2005). "Capturing the essence of a brand from its history: The case of Scottish tourism marketing", Journal of Brand Management, 13(2), pp. 134-147.

Zismer, D.K. (2013). "The Promise of the Brand: How Health System Leaders Are Guiding the Transition to Health Services Integration", Journal of Healthcare Management, 58(1), pp. 12-14.

Zott, C. \& Amit, R. (2008). "The fit between product market strategy and business model: implications for firm performance", Strategic Management Journal, 29(1), pp. 1-26. 


\section{Handbook of Service Science, Volume II}

\section{Table of Contents}

Foreword I, Martin Fleming

Foreword II, Irene $\mathrm{Ng}$

Preface

Contributors

1. Introduction: Why Another Handbook?

Paul P. Maglio, Cheryl A. Kieliszewski, James C. Spohrer, Kelly Lyons, Lia Patrício and Yuriko Sawatani

Part 1: Service Experience - On the Human-centered Nature of Service

2. Service Timing: Designing and Executing Service in a Dynamic Environment Ruth N. Bolton

3. Designing Service Systems to Enhance Perceived Decision Control Sriram Dasu, and Alexandra-Brunner Sperdin

4. The Sequence of Service: An Affect Perspective to Service Scheduling Michael J. Dixon and Liana Victorino

5. Customer Adoption of AI in Service Encounters Amy Ostrom, Darima Fotheringham, and Mary Jo Bitner

6. Optimal Structure of Experiential Services: Review and Extensions Guillaume Roels

7. A Human-centered, Multidisciplinary, and Transformative Approach to Service Science: A Service Design Perspective Daniela Sangiori, Filipe Lima, Lia Patrício, Maíra Prestes Joly, and Cristina Favini

8. Emerging Design Research Themes: A Research Review from Design, Service, and Management Studies Yuriko Sawatani 
9. High-tech vs. High Touch Service Design in Healthcare: A Case for Considering the Emotional Biorhythm of the Patient in Technology Interventions

Alexis Strong and Rohit Verma

10. Customer Experience Analytics: Dynamic Customer-Centric Model Mohamed Zaki and Andy Neely

\section{Part 2: Service Systems - On the Nature of Service Interactions}

11. The Future of Service Systems: From Synergetics to Multi-Sided Platforms Jennifer Chandler

12. Using Employees' Collective Intelligence for Service Innovation: Theory and Instruments Niels Feldman, Hansjörg Fromm, Gerhard Satzger, and Ronny Schüritz

13. A Multilayer Framework for Service System Analysis Robert Frost, Michael Cheng, and Kelly Lyons

14. People and Social Interaction: Drivers of Service Innovation Cheryl A. Kieliszewski and Laura Challman Anderson

15. Queues in Service Systems: Some Unusual Applications Luna An, Mallika Machra, Abigail M. Moser, Sanja Simonovikj and Richard C. Larson

16. Clarifying the Concept of Smart Service Systems Chiehyeon Lim and Paul P. Maglio

17. Exploring the Journey to Services Veronica Martinez, Andy Neely, Chander Velu, Stewart Leinster-Evans, and Dav Bisessar

18. Digital Workers in Nested, Networked Holistic Service Systems: A New Workplace Culture from a Service Science Perspective Paolo Piciocchi, Clara Bassano, Maria Cristina Pietronudo, and James C. Spohrer

19. Visualizing and Improving Service Processes with PCN Analysis Scott E. Sampson

\section{Part 3: Service Ecosystems - On the Broad Context of Service}

20. Value-in-Context: An Exploration of the Context of Value and the Value of Context Melissa Archpru Akaka and Glenn Parry

21. On the Evolution of Service Ecosystems: A Study of the Emerging API Economy Rahul C. Basole 
22. Institutionalization Process of Service Innovation: Overcoming Competing Institutional Logics in Service Ecosystems

Elina Jaakkola, Leena Aarikka-Stenroos, and Paavo Ritala

23. Innovation in Sociomaterial Practices. The Case of IoE in The Healthcare Ecosystem Cristina Mele and Tiziana Russo Spena

24. Toward the Service Science of Education

Oleg V. Pavlov and Frank Hoy

25. Leveraging Big Data Platform Technologies and Analytics to Enhance Smart City Mobility Services

Robin G. Qiu, Tianhai Zu, Ying Qian, Lawrence Qiu, and Youakim Badr

26. Population Health as a Network of Services: Integration of Health, Education, and Social Services

William B. Rouse, Kara M. Pepe, and Michael M. E. Johns

27. Incremental and Radical Service Innovation in Healthcare

Peter Samuelsson, Lars Witell, Patrik Gottfridsson, and Mattias Elg

\section{Part 4: Challenges - On Rethinking the Theory and Foundations of Service Science}

28. Further Advancing Service Science with Service-Dominant Logic: Service Ecosystems, Institutions, and their Implications for Innovation

Melissa Archpru Akaka, Kaisa Koskela-Huotari, and Stephen L. Vargo

29. On the Ethical Implications of Big Data in Service Systems

Christoph F. Breidbach, Michael Davern, Graeme Shanks, and Ida Asadi-Someh

30. Service-Dominant Logic: Inward and Outward Views

Luigi Cantone, Pierpaolo Testa, and Teresa Marrone

31. Service Economies and Complexity

Benoît Desmarchelier

32. A Perspective on the Field of Service Science

Janet R. McColl-Kennedy

33. Embedding Humans into Service Systems Analysis: The Evolution of Mathematical Thinking about Services

Alexandra Medina-Borja

34. The Demolition of Service Scientists' Cultural-boundaries 
Francesco Polese, Sergio Barile, Vincenzo Loia, and Luca Carrubbo

35. Capturing Value in the Service Economy Jochen Wirtz and Michael Ehret

36. Service as Intersubjective Struggle Yutaka Yamauchi 